\title{
Technical assessment of electric heat boosters in low-temperature district heating based on combined heat and power analysis
}

\author{
Cai, Hanmin; You, Shi; Wang, Jiawei; Bindner, Henrik W.; Klyapovskiy, Sergey
}

Published in:

Energy

Link to article, DOI:

10.1016/j.energy.2018.02.084

Publication date:

2018

Document Version

Peer reviewed version

Link back to DTU Orbit

Citation (APA):

Cai, H., You, S., Wang, J., Bindner, H. W., \& Klyapovskiy, S. (2018). Technical assessment of electric heat boosters in low-temperature district heating based on combined heat and power analysis. Energy, 150, 938-49. https://doi.org/10.1016/j.energy.2018.02.084

\section{General rights}

Copyright and moral rights for the publications made accessible in the public portal are retained by the authors and/or other copyright owners and it is a condition of accessing publications that users recognise and abide by the legal requirements associated with these rights.

- Users may download and print one copy of any publication from the public portal for the purpose of private study or research.

- You may not further distribute the material or use it for any profit-making activity or commercial gain

- You may freely distribute the URL identifying the publication in the public portal 


\section{Accepted Manuscript}

Technical assessment of electric heat boosters in low-temperature district heating based on combined heat and power analysis

Hanmin Cai, Shi You, Jiawei Wang, Henrik W. Bindner, Sergey Klyapovskiy

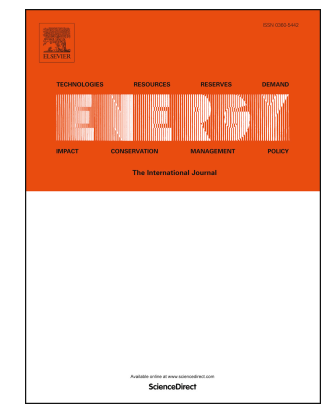

PII:

S0360-5442(18)30312-8

DOI:

10.1016/j.energy.2018.02.084

Reference: $\quad$ EGY 12384

To appear in: Energy

Received Date: 1 November 2017

Revised Date: 23 January 2018

Accepted Date: 17 February 2018

Please cite this article as: Cai H, You S, Wang J, Bindner HW, Klyapovskiy S, Technical assessment of electric heat boosters in low-temperature district heating based on combined heat and power analysis, Energy (2018), doi: 10.1016/j.energy.2018.02.084.

This is a PDF file of an unedited manuscript that has been accepted for publication. As a service to our customers we are providing this early version of the manuscript. The manuscript will undergo copyediting, typesetting, and review of the resulting proof before it is published in its final form. Please note that during the production process errors may be discovered which could affect the content, and all legal disclaimers that apply to the journal pertain. 


\title{
Technical Assessment of Electric Heat Boosters in Low-Temperature District Heating based on Combined Heat and Power Analysis
}

\author{
Hanmin Cai ${ }^{\mathrm{a}}$, Shi You ${ }^{\mathrm{a}, *}$, Jiawei Wang ${ }^{\mathrm{a}}$, Henrik W. Bindner ${ }^{\mathrm{a}}$, Sergey Klyapovskiy ${ }^{\mathrm{a}}$ \\ ${ }^{a}$ Technical University of Denmark, 2800 Kgs. Lyngby, Denmark
}

\begin{abstract}
This paper provides a technical assessment of electric heat boosters (EHBs) in low-energy districts. The analysis is based on a hypothetical district with 23 terraced single-family houses supplied by both a low-temperature district heating (LTDH) network and a lowvoltage network (LVN). Two case studies are provided to show the active role of EHBs in a smart energy system (SES). The first case compares annual heat and power flow analyses for LTDH at five supply temperature levels, focusing on their impacts. The results show that district heating network (DHN) losses can be reduced by $35 \%$ if the supply temperature is reduced from $70^{\circ} \mathrm{C}$ to $50^{\circ} \mathrm{C}$, but the LVN peak power will have to be increased by up to $2 \%$ using heat boosting. The second case further aggregates EHBs to provide a fuel shift (FS) service for the DHN. The results show that while LVN peak power was increased by up to $4.3 \%$, the basic power production and peak boiler usage for DHN could be reduced by as much as $15 \%$ and $48 \%$, respectively. In summary, lower supply temperatures and intelligent components can improve system efficiency and turn the DHN into an integrated part of a SES.
\end{abstract}

Keywords: Smart energy systems; 4GDH; Low-temperature district heating; Electric heat boosters; Fuel shift; Combined heat and power.

\section{Introduction}

Denmark is aiming at a 100\% renewable-based electricity and heating sector by 2035 and a complete transition to a renewable-based energy system by 2050 [1]. Such ambitious targets demand considerable effort involving integration of intermittent renewable sources 5 and energy conservation. In recent years, a large number of renewable energy sources, such as wind power plants, have been connected to the Danish energy system. Meanwhile, energy

\footnotetext{
${ }^{*}$ Corresponding author

Email addresses: hacai@elektro.dtu.dk (Hanmin Cai), sy@elektro.dtu.dk (Shi You), jiawang@elektro.dtu.dk (Jiawei Wang), hwbi@elektro.dtu.dk (Henrik W. Bindner), seklya@elektro.dtu.dk (Sergey Klyapovskiy)
} 


\begin{tabular}{|c|c|c|c|c|c|}
\hline & Nomenclature & & & & \\
\hline A & network incidence matrix [-] & Abbrevation & & $\sigma$ & standard deviation [-] \\
\hline$A r$ & surface area of tank $\left[\mathrm{m}^{2}\right]$ & Agg & Aggregator & & \\
\hline$B$ & susceptance $\left[\Omega^{-1}\right]$ & CHP & Combined Heat and Power & Subscripts & and superscripts \\
\hline B & incidence matrix [-] & DCW & District Cold Water & amb & ambient \\
\hline$c$ & water specific heat $\left[\mathrm{kJ} /\left(\mathrm{kg} \cdot{ }^{\circ} \mathrm{C}\right)\right]$ & DH & District Heating & $\mathrm{cw}$ & cold water \\
\hline $\mathrm{C}$ & conversion matrix [-] & DHN & District Heating Network & $\mathrm{d}$ & downstream node \\
\hline$d$ & inner pipe diameter $[\mathrm{m}]$ & DHW & Domestic Hot Water & des & desired \\
\hline$E$ & energy [MWh] & DHO & District Heating Operator & el & electric \\
\hline$G$ & conductance $\left[\Omega^{-1}\right]$ & EHB & Electric Heat Booster & est & estimated \\
\hline$I$ & current $[\mathrm{A}]$ & EL & Electric Power & $\mathrm{g}$ & ground \\
\hline$L$ & pipe length $[\mathrm{m}]$ & FS & Fuel Shift & in & incoming \\
\hline$\dot{m}$ & mass flow rate $[\mathrm{kg} / \mathrm{s}]$ & LTDH & Low-Temperature District Heating & $l$ & pipe index \\
\hline$M$ & tank water mass $[\mathrm{kg}]$ & LVN & Low-Voltage Network & $\max / \min$ & maximum/minimum \\
\hline$p$ & pressure $[\mathrm{kPa}]$ & SES & Smart Energy System & $m, n$ & bus index \\
\hline$P$ & active power $[\mathrm{kW}]$ & $\mathrm{SH}$ & Space Heating & out & out flowing \\
\hline$Q$ & reactive power $[\mathrm{kVAR}]$ & $\mathrm{SF}$ & Simultaneity Factor & q & node flow \\
\hline$S$ & complex power $[\mathrm{kVA}]$ & & & quo & quota \\
\hline$t$ & time period $[\mathrm{min}]$ & Greek symbol & & $\mathrm{r}$ & return \\
\hline$T$ & temperature $\left[{ }^{\circ} \mathrm{C}\right]$ & $\delta$ & voltage angle $[\mathrm{rad}]$ & s & supply \\
\hline$u$ & control decision [-] & $\Delta$ & difference [-] & serv & service pipe \\
\hline$U$ & heat transfer coefficient $\left[\mathrm{kW} /\left(\mathrm{m}^{2} \cdot \mathrm{K}\right)\right]$ & $\Phi$ & thermal power $[\mathrm{kW}]$ & tk & $\operatorname{tank}$ \\
\hline$V$ & voltage $[\mathrm{V}]$ & $\lambda$ & friction factor $[-]$ & tap & tap water draw \\
\hline$\dot{V}_{\mathrm{o}}$ & volume flow rate $\left[\mathrm{m}^{3} / \mathrm{s}\right]$ & $\mu$ & expected value | & $\mathrm{u}$ & upstream node \\
\hline $\mathbf{Y}$ & bus admittance matrix [-] & $\rho$ & density $\left[\mathrm{kg} / \mathrm{m}^{3}\right]$ & & \\
\hline
\end{tabular}

efficiency measures have been taken in the heating sector as the Danish Building Regulations have set a progressively lower energy consumption framework [2]. These new developments demand a rethinking and redesign of the current energy system, i.e. a smart energy system [3.

Instead of the traditional separate operation of the various energy sectors, what is needed is a smart energy system (SES) approach combining multiple smart grid infrastructures [4]. We need to identify synergies to achieve an optimal solution for each individual sector as well as for the overall energy system [5]. For instance, to achieve the 2035 targets, we need to coordinate the operation of the electricity and heat sectors. More concretely, intermittent wind farm power output is challenging the operation of the Danish power system, which currently relies on neighbouring countries for a large part of its balancing needs. Occasionally, Denmark exports electricity to neighbours at negative prices [6]. As neighbouring countries integrate renewable energy into their own energy systems, more balancing capacity will be needed in the future [7. Research shows that storage in the electricity sector will be insufficient and more capacity needs to be found in other sectors, such as district heating (DH) [3]. This is a well-developed and efficient heating solution in Scandinavian countries and will operate at lower supply temperature levels as more lowenergy buildings are constructed. The concept of low-temperature district heating (LTDH) or $4^{\text {th }}$ generation district heating $(4 \mathrm{GDH})$ represents a paradigm shift in $\mathrm{DH}$ development and features a low supply temperature and intelligent control of DH system components [4]. The former will provide benefits such as heat loss reduction, easier access to renewable sources, and more efficient waste heat recovery, while the latter will enable DH systems to be 
integrated in smart energy systems. Meanwhile DH systems will require more power-to-heat

conversions as combined heat and power (CHP) plants play a smaller role in future energy systems due to an increasing renewable share [8].

A lot of research has focused on one or more of the aspects mentioned above, and some has focused on identifying possible synergy across sectors. Mancarella [9] provides a comprehensive overview of existing concepts and the tools needed to do research in multienergy systems. Li et al. [10] propose using the water in district heating network (DHN) as energy storage for decoupling CHP operation in order to balance wind power fluctuation and reduce curtailment. Cai et al. [11] consider thermal loads as flexible cross-sector resources to assist SES operations and demonstrate coordinated demand response [12. Some research has focused on the impact of lowering DH supply temperature. Østergaard et al. [13] have shown that the space heating ( $\mathrm{SH}$ ) needs of typical Danish single-family houses can already be satisfied for large parts of the year using LTDH. However, a supply temperature as low as $60^{\circ} \mathrm{C}$ is not sufficient to provide domestic hot water (DHW) without increasing the risk of Legionella contamination. Yang et al. 14 list several alternative solutions, while Zvingilaite et al. [15] report that the most economical solution is to use a supplementary electric heater. Park et al. [16] studied a multi-storey building supplied by LTDH with varying temperature levels. They argue that there are optimal supply and return temperatures that minimize the net operation cost. Ommen et al. [17] discovered that the impact of variation in the $\mathrm{DH}$ temperature on the coefficient of system performance is different for systems supplied by central HP from those supplied by extraction CHP. Elmegaard et al. [18] suggest that the benefits from reduced heat losses in LTDH networks are not sufficient to make it more competitive than conventional systems due to the high share of DHW in low-energy buildings. Østergaard et al. [19] compare LTDH using booster heat pumps with LTDH using natural gas boilers, suggesting that LTDH with booster heat pumps is the better option. Yang et al. 20] investigated using instantaneous heat exchanger units to prepare DHW and suggest that as the better option for supply temperatures of $50{ }^{\circ} \mathrm{C}$ and $65^{\circ} \mathrm{C}$. A few researchers have focused on active control to facilitate the operation of conventional DH systems. For instance, DH load creates thermal peaks [21, 22], which may lead to sub-optimal dispatch of co-generation units, and therefore increase primary energy consumption 23. The peak thermal load may also mean the network is over-dimensioned. To shave the peak, Johansson et al. 24] deploys agent-based load control in DH substations and reduces peak demand in the DHN through short-term shifting of SH load. However, these literature sources do not consider the additional operational benefits from using active heat boosting equipment in an SES, which may influence the economic outlook.

This paper therefore set out to assess two aspects of 4GDH in an SES context, namely lower supply temperature levels and intelligent control of substations, including heat boosting devices using electricity. Their small investment cost and simple operation mean that heat boosting solutions using supplementary electric heaters are likely to be widely present in an energy system that integrates LTDH. The device is called an electric heat booster (EHB) and will be the focus throughout this paper. Collectively, EHBs can form a significant flexibility portfolio for the system operators. For example, the following sections will consider using EHBs to provide a fuel shift (FS) service to the LTDH network. The term 
FS will be explained and formulated mathematically in the next section. To the best of the authors' knowledge, no previous research has either explicitly considered EHBs as flexible cross-sector coupling or designed a service to support LTDH at planning and operation stages.

This paper is organized as follows: The next section presents the methodology, including the modelling of the DHN, low-voltage network (LVN) and EHBs with FS controller design at district level. Section 3 then provides two case studies, in which the impacts of LTDH supply temperature levels are investigated and the FS service is evaluated. Finally, section 4 draws conclusions and makes remarks on future work.

\section{Methodology}

\subsection{System description}

To facilitate discussion, an abstract representation of a building's connection to the DHN and LVN is illustrated in Figure 1. In a fully renewable based Danish energy system, electricity will largely come from wind power transmitted across the country, and LTDH will be more dependent on local low temperature renewable sources (such as geothermal energy) and improved waste heat recovery. Substations will use the LTDH network to support the $\mathrm{SH}$ load while DHW is prepared using EHBs. The energy flow inside an EHB is shown in Figure 2. Both electric power from the LVN and thermal power from the DHN can be used to heat up tank water. While electric power is dependent on voltage over the EHB, thermal power depends on the flow rate and temperature drop.

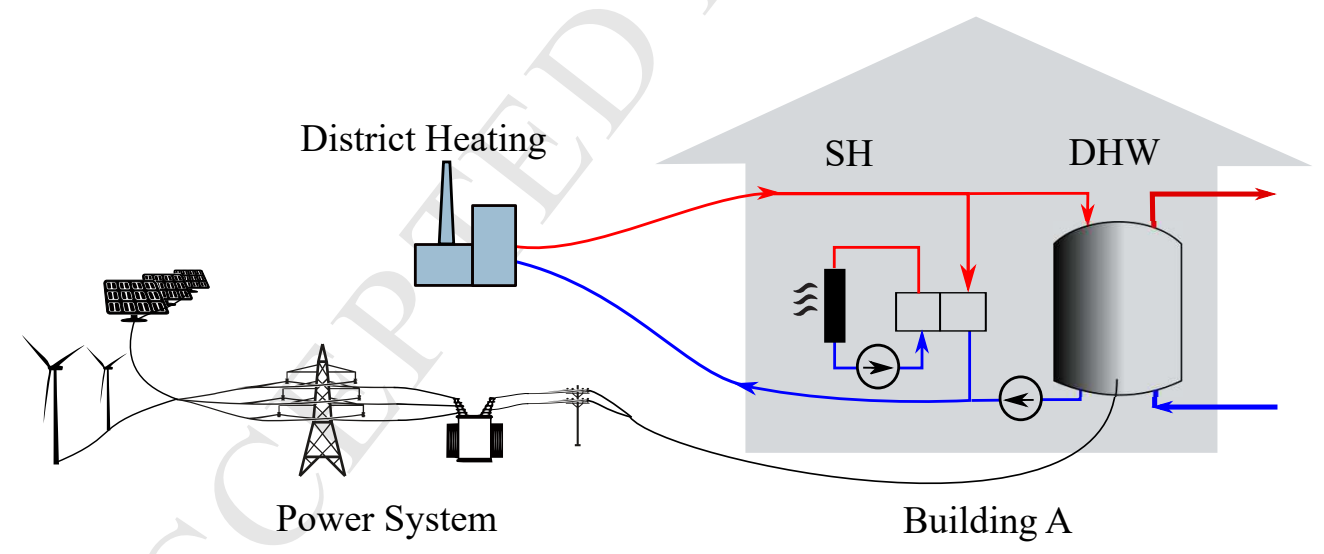

Figure 1: EHB is connected to both DHN and LVN

A real-world example of Figure 1 is shown in Figure 3, where an SES lab called "SYSLAB" has been developed to research synergies across energy sectors from building active components and deploying intelligent control. More specifically, the physical installation of the EHB (shown in Figure 4) contributes to its heat boosting function. Figure 5 shows the architecture of the underlying information and communications technology (ICT) infrastructure that supports both centralized and distributed control. Mathematical models were used to analyse the system described above. These models support the simulation in MATLAB and are described in detail in the rest of this section. 


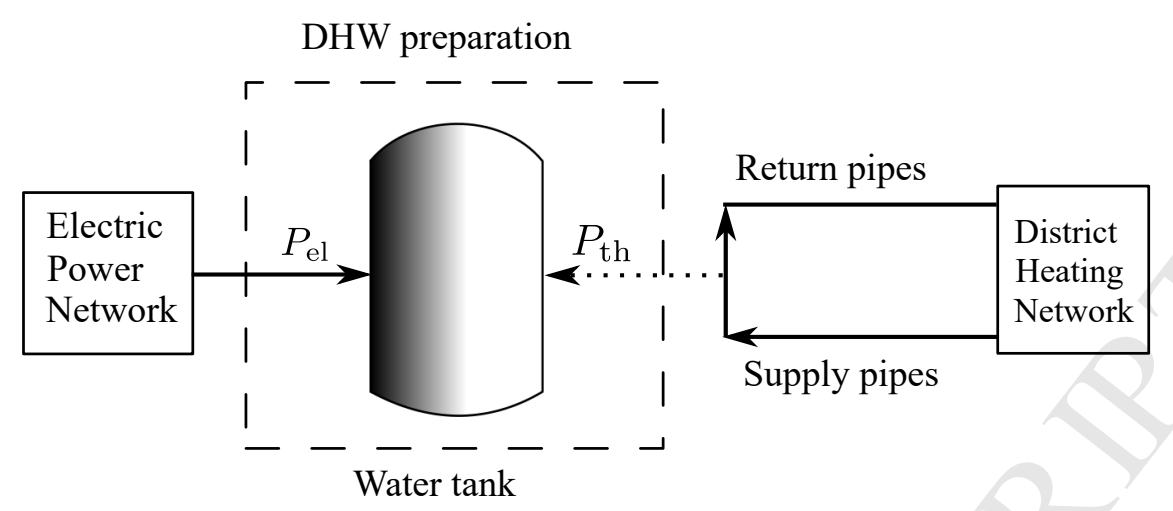

Figure 2: Simplified view of energy flow
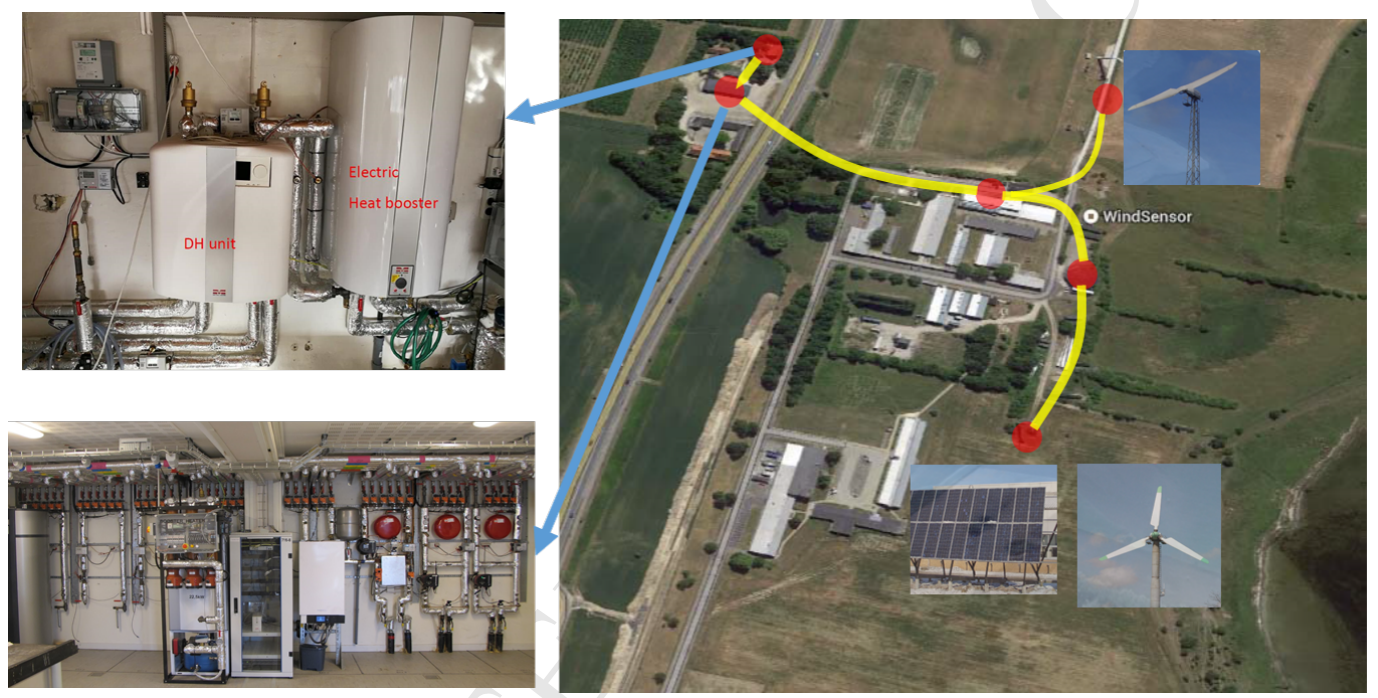

Figure 3: SYSLAB - A flexible intelligent laboratory for integrated energy system research. The red dots show the location of components; yellow lines indicate network connections

\subsection{DHN modelling}

DHN characteristics were modelled in detail to reflect operation constraints, whereas dynamics (such as the temperature distribution along the pipes) were ignored to keep the simulation simple. Moreover, the supply temperature was assumed to be constant throughout the year, and heat transfer delays were also neglected. Hydraulic models are formulated in Equations 1- 6 and thermal models are provided in Equations 7- 8, Equation 1, which describes the continuity law for incompressible water flow in a compact form [25], was used to calculate the flow rate in each pipe:

$$
\mathbf{A} \dot{\mathbf{m}}=\dot{\mathbf{m}}_{\mathrm{q}}
$$

where $\mathbf{A}$ is the network incidence matrix, and $\dot{\mathbf{m}}$ and $\dot{\mathbf{m}}_{\mathrm{q}}$ are vectors of pipe and nodal mass flow rate respectively. Every node connected with a low-energy building is here called a load node. The rate of mass flow discharged to each load node consists of $\dot{m}_{\mathrm{q}, \mathrm{SH}}$ for SH and 


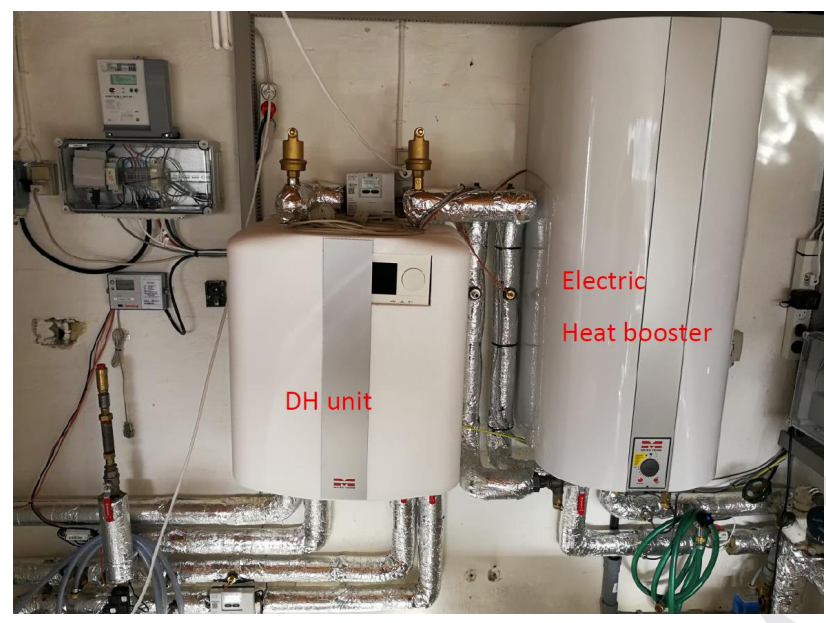

Figure 4: Electric heat booster

$\dot{m}_{\mathrm{q}, \mathrm{DHW}}$ for DHW preparation, as in Equation 2.

$$
\dot{m}_{\mathrm{q}}=\dot{m}_{\mathrm{q}, \mathrm{SH}}+\dot{m}_{\mathrm{q}, \mathrm{DHW}}
$$

The rate of load node mass flow due to $\mathrm{SH}$ is described by Equation 3.

$$
\dot{m}_{\mathrm{q}, \mathrm{SH}}=\frac{\Phi_{\mathrm{SH}}}{c\left(T_{\mathrm{serv}}-T_{\mathrm{r}}\right)}
$$

where $T_{\text {serv }}$ and $T_{\mathrm{r}}$ are respectively the temperatures of the service pipe and the return pipe at load node, while $\Phi_{\mathrm{SH}}$ is $\mathrm{SH}$ power at the same node.

The consumed pump power can be calculated as in Equations 4- 6 [26]:

$$
\begin{gathered}
\Delta p=-\frac{8 \lambda L}{d^{5} \pi^{2} \rho} \cdot \dot{m}^{2} \\
\Delta p_{\text {pump }}=\Delta p_{\mathrm{s}}+\Delta p_{\mathrm{r}}+\Delta p_{\text {min }} \\
P_{\text {pump }}=\frac{\Delta p_{\text {pump }}}{\eta_{\text {pump }}} \cdot \dot{V}_{\mathrm{o}}
\end{gathered}
$$

where $P_{\text {pump }}$ is the required pumping electric power, $\Delta p_{\mathrm{s}}$ and $\Delta p_{\mathrm{r}}$ are the total pressure drops from the most peripheral substation to the main circulation pump in respectively the supply and return pipes, $\Delta p_{\min }$ is the minimum differential pressure at the most peripheral substation, $\eta_{\text {pump }}$ is the total conversion efficiency for the circulation pump, and $\dot{V}_{\mathrm{o}}$ is the volume flow rate.

Multiple incoming flows at a given node were assumed to be well-mixed so that the temperature of the flow leaving the node can be calculated as in Equation 7 [25]:

$$
\left(\sum \dot{m}_{\text {out }}\right) T_{\text {out }}=\sum\left(\dot{m}_{\text {in }} T_{\text {in }}\right)
$$




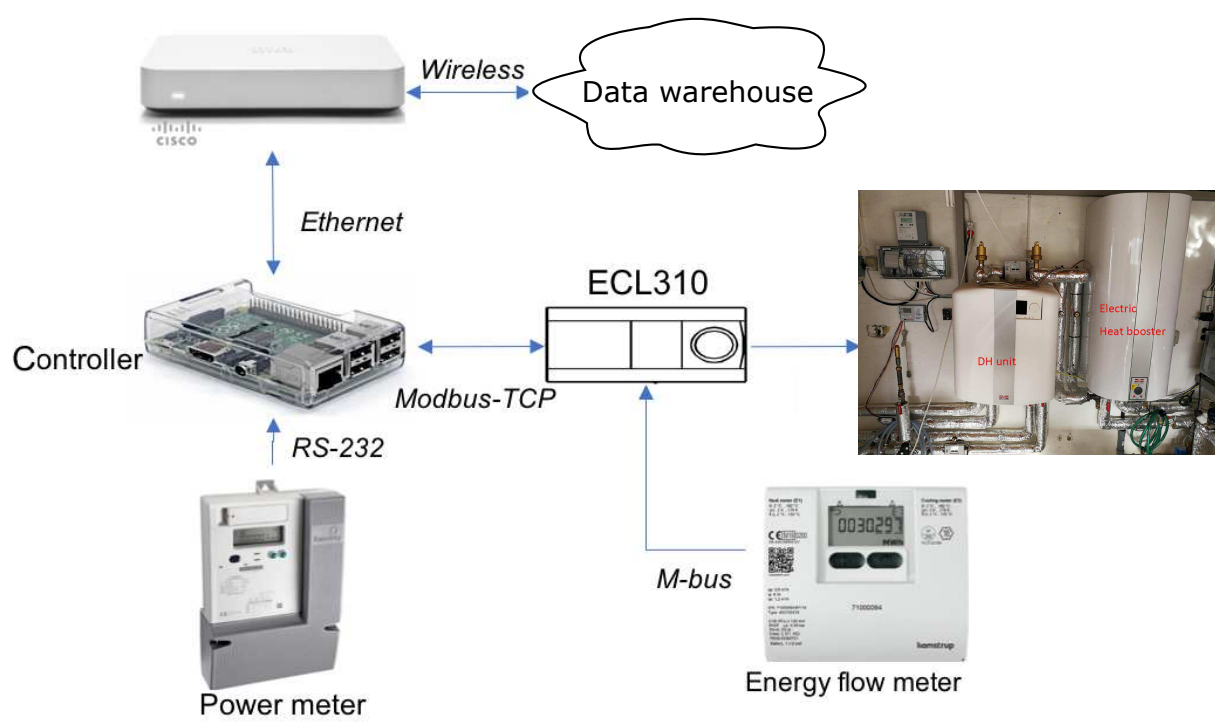

Figure 5: Control and communication - enabling smart response from EHBs

where $T_{\text {out }}$ is the mixed temperature, $\dot{m}_{\text {out }}$ is the mass flow rate leaving the node, $\dot{m}_{\text {in }}$ is the mass flow rate entering the node, and $T_{\text {in }}$ is the temperature of the incoming flow. The bypass flow at critical nodes was incremented in an iterative process to simulate the bypass valve thermostat control that keeps the temperature drop within $5^{\circ} \mathrm{C}[27$. The pipe flow rate will be constrained by the velocity limit of the pipes, but must also guarantee the minimum differential pressure required on the end-user side.

The temperature drop along the pipes can be described by Equation 8 [25]:

$$
T_{\mathrm{d}, l}=T_{\mathrm{g}}+\left(T_{\mathrm{u}, l}-T_{\mathrm{g}}\right) e^{-\frac{U_{l} L_{l}}{c \dot{m}_{l}}}
$$

where $T_{\mathrm{d}, l}$ and $T_{\mathrm{u}, l}$ denote the temperatures at the upstream and the downstream nodes of pipe $l, T_{\mathrm{g}}$ refers to the soil temperature, $U_{l}$ and $L_{l}$ denote the heat loss coefficient and the pipe length, and $\dot{m}_{l}$ denotes the pipe flow rate.

\subsection{LVN modelling}

The LVN was also modelled to investigate impact of heat boosting and the FS service on the LVN. The load power at each load node varies, so the total power feed-in from the external grid, as well as the power losses, will also vary.

Applying Kirchhoff's Current Law at each bus in the LVN allows a set of nodal equations to be derived and written in a compact form as in Equation 9.

$$
\mathbf{I}=\mathbf{Y V}
$$

where $\mathbf{I}$ denotes the vector of net current injection, $\mathbf{Y}$ is the bus admittance matrix, and $\mathbf{V}$ is the vector of the bus voltage phasor. The complex power at each bus $S$ is expressed in 
Equation 10:

$$
S_{n}=P_{n}+j Q_{n}=V_{n} I_{n}
$$

The real and imaginary parts of the complex power, i.e. the active and reactive power at each bus, can be respectively expressed in Equations $11-12$

$$
\begin{gathered}
P_{m}=\left|V_{m}\right| \sum_{n=1}^{N}\left|V_{n}\right|\left(G_{m n} \cos \delta_{m n}+B_{m n} \sin \delta_{m n}\right) \\
Q_{m}=\left|V_{m}\right| \sum_{n=1}^{N}\left|V_{n}\right|\left(G_{m n} \sin \delta_{m n}-B_{m n} \cos \delta_{m n}\right)
\end{gathered}
$$

where both active and reactive power at bus $n$ are represented by its voltage magnitude $\left|V_{n}\right|$ and $\left|V_{m}\right|$ of the buses $m$ connected to it, the susceptance of the distribution line is $B_{m n}$ and its conductance is $G_{m n}, \delta_{m n}$ is the voltage angle between bus $m$ and $n$, and $N$ refers to total number of nodes.

We used the Newton-Raphson method to solve the above equations and provide a power flow analysis of the LVN.

\subsection{Electric heat booster modelling}

The setup used in this research assumed a water tank volume larger than 3 litres is on the secondary side, which requires heat boosting to satisfy the hygiene requirement according to the German Standard W551 [28]. The heat boosting concept is shown in Figure 6a. DH flow exchanges heat with cold tank water through a DH coil placed in the middle of the tank. At the same time, an electrical resistance is present and uses electricity to boost water temperatures up to $55^{\circ} \mathrm{C}$ and occasionally to $60^{\circ} \mathrm{C}$. The Danish Code of Practice for Water Supply Installations [29] requires tap water to be between $40^{\circ} \mathrm{C}$ and $45^{\circ} \mathrm{C}$ depending on its purpose. To keep things simple, $42^{\circ} \mathrm{C}$ was used as the tap water temperature. Detailed modelling of Figure 6a adds considerable complexity to controller design. Since the energy consumption is the most important parameter in an integrated energy system context, a simple single-layer water tank model focusing on energy balance was used. A single-layer model treats the water in the tank as a homogeneous layer, ignoring the fluid dynamics of water being drawn, and cold water fed in and heated. Figure $6 \mathrm{~b}$ shows the power exchange, which is formulated in Equation 13:

$$
c M \dot{T}_{\mathrm{tk}}=\Phi^{\prime}-c \dot{m}_{\mathrm{tk}}\left(T_{\mathrm{tk}}-T_{\mathrm{cw}}\right)-U A r\left(T_{\mathrm{tk}}-T_{\mathrm{amb}}\right)
$$

where $A r$ is the tank surface area, $T_{\mathrm{tk}}$ is the tank water temperature, $T_{\mathrm{cw}}$ is the cold water temperature, $T_{\mathrm{amb}}$ is the ambient temperature of the $\mathrm{EHB}, \dot{m}_{\mathrm{tk}}$ is the rate of water drawn from the water tank, and $\Phi^{\prime}$ is the heat power injected into the tank by DH coil $\Phi$ or electrical element $P$ :

$$
\Phi^{\prime}=\Phi+P=c \dot{m}_{\mathrm{q}, \mathrm{DHW}}\left(T_{\mathrm{serv}}-T_{\mathrm{r}}\right) u+\bar{P}(1-u)
$$




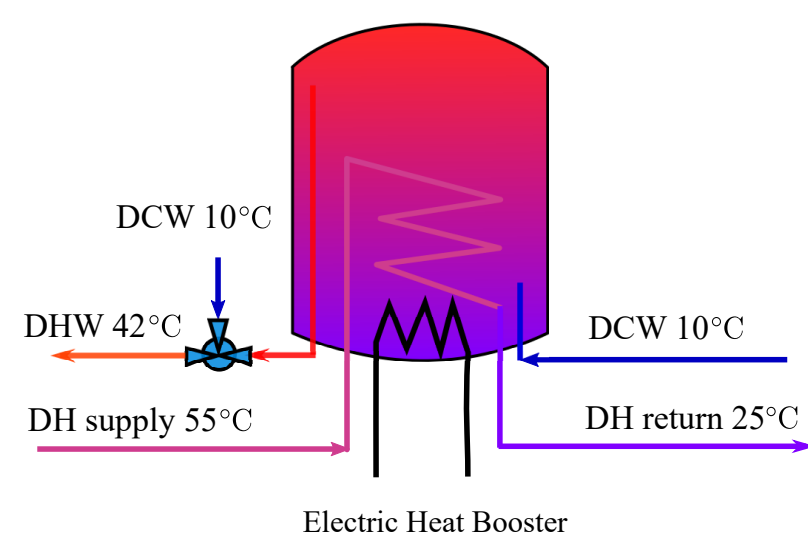

(a) Internal structure of an electric heat booster connected to LTDH at $T_{s}=55^{\circ} \mathrm{C}$

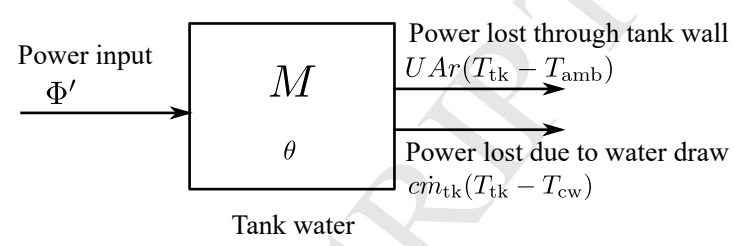

(b) Single-layer EHB energy balance

Figure 6: EHB structure and energy balance for the single-layer model

where $u$ is the control decision to use $\mathrm{DH}$ coil or the electrical element to heat DHW. $T_{\mathrm{cw}}$ was assumed to be $10^{\circ} \mathrm{C}$ and $T_{\text {amb }}$ was assumed to be $18^{\circ} \mathrm{C}$, both constant throughout the year.

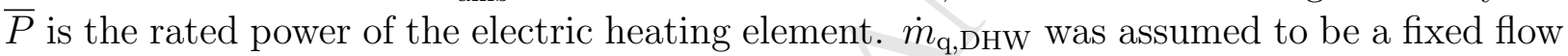
rate of $150 \mathrm{l} / \mathrm{h}$. Valve dynamics were ignored. To simplify matters, the return temperature at the substation was assumed to be constant, though in practice it can be manually set by the user. In the simulation, $T_{\mathrm{r}}$ was set to be $30^{\circ} \mathrm{C}$ less than the supply temperature for all the substations and neglect dynamics inside heat exchangers.

The heat boosting decision variable $u$ in Equation 14 is formulated in Equation 15 by taking into account the heat exchanger temperature loss $\Delta T$.

$$
u= \begin{cases}1, & \text { if } T_{\mathrm{tk}}<T_{\mathrm{s}}-\Delta T \\ 0, & \text { otherwise }\end{cases}
$$

The control logic formulated above never deployed DH and electric heating at the same time. The tank water temperature set point was assumed to be $55^{\circ} \mathrm{C}$ with a thermostat dead-band of $1^{\circ} \mathrm{C}$. Moreover, the water at the user's tap was obtained by mixing hot water from the tank with cold water. This can be expressed as Equation 16.

$$
\dot{m}_{\mathrm{tk}}=\min \left\{\frac{42^{\circ} \mathrm{C}-10^{\circ} \mathrm{C}}{T_{\mathrm{tk}}-10^{\circ} \mathrm{C}}, 1\right\} \times \dot{m}_{\mathrm{tap}}
$$

where $\dot{m}_{\text {tap }}$ is the water drawn at user's tap created using the Danish Standard profile [29]. The whole simulation and control process is summarized in Figure 7.

\subsection{Network dimensions and demand profile}

The low-energy district of 23 terraced single-family houses considered here was assumed to have been built according to the most recent Danish Building Regulations 2015 (BR15). 


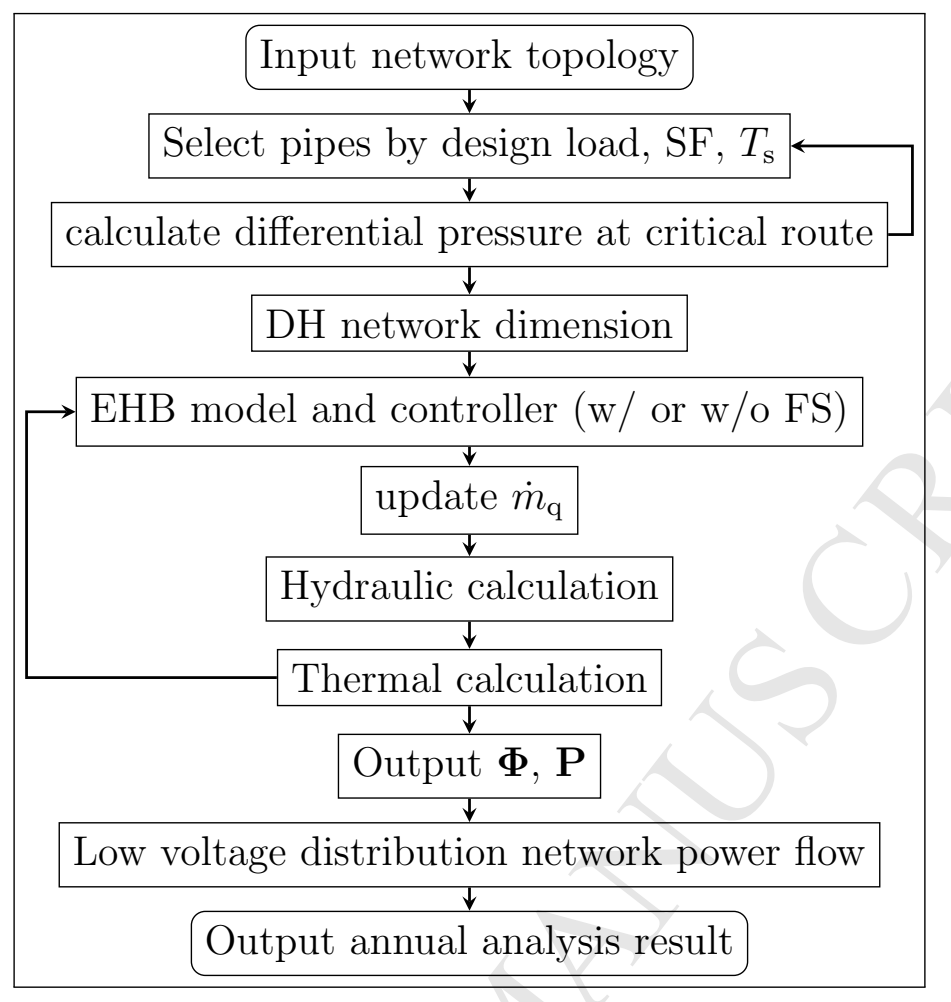

Figure 7: Simulation flow chart

These require that annual energy demand for heating, ventilation, cooling and DHW preparation should not exceed the energy performance framework calculated as $30+1000 /$ (total heated floor area) $\mathrm{kWh} / \mathrm{m}^{2} / \mathrm{y}$ [2].

All the houses were assumed to have a heated floor area of about $140 \mathrm{~m}^{2}$ with $3 \sim 4$ occupants, which gives an annual total energy demand of 5.2MWh. The network topology was based on the building density of the outskirts of Copenhagen. This makes the network losses, which depend greatly on pipe lengths, more representative. The greenfield design of the dimensions of the DH network takes into account the network topology, design load and simultaneity factor (SF). Details on the methodology and the numerical values of SF can be found in Li and Svendsen (2012) [27]. The network topology, including connections and the length of pipes, was determined by sketching based on a district in the outskirts of Copenhagen using Google map. The network topology is shown in Figure 8. For the DH system, the design load was assumed to be $3 \mathrm{~kW}$ for $\mathrm{SH}$ and $5.2 \mathrm{~kW}$ for DHW. A 10-bar system with minimum network static pressure of 2 bars was used in the network dimensioning. The pressure drop on the end-user side was assumed to be $50 \mathrm{kPa}$, taking into account the minimum differential pressure and local pressure loss. The network was designed for supply/return temperatures of $50 / 20{ }^{\circ} \mathrm{C}, 55 / 25^{\circ} \mathrm{C}, 60 / 30^{\circ} \mathrm{C}, 65 / 35^{\circ} \mathrm{C}, 70 / 40^{\circ} \mathrm{C}$, and $80 / 40^{\circ} \mathrm{C}$, but supply/return temperatures of $80 / 40^{\circ} \mathrm{C}$ are not discussed in this paper because they fall outside the definition of LTDH. Pipes were selected from existing commercial products. Network dimension results are summarized in Figure 9 and Table 1. To make valid comparisons, the 
DH network was assumed to operate at a constant supply temperature level throughout the year with a temperature drop of $30^{\circ} \mathrm{C}$. Figure 9 shows that the network dimensions do not change when the temperature drop is the same. This is because the methodology proposed by Li and Svendsen [27] utilizes differential pressure over critical nodes as the decisive factor for network dimensioning. So the same network dimensions were used for all the analyses.

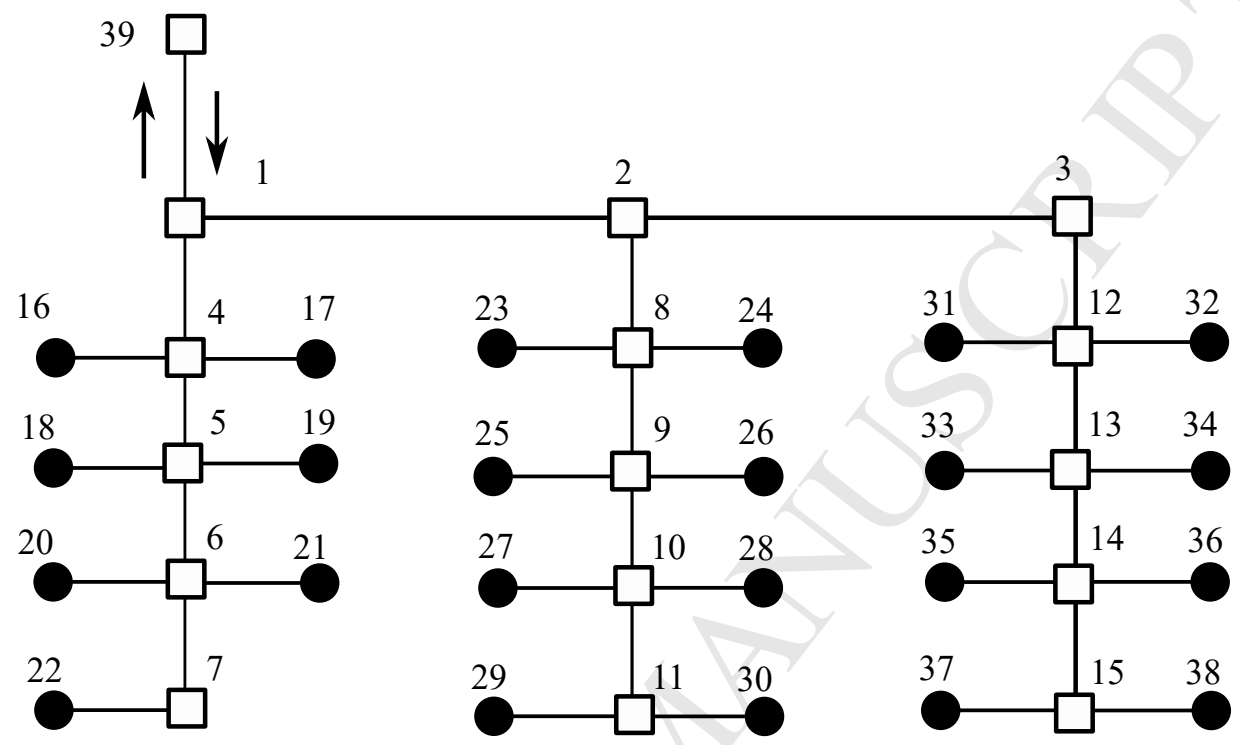

Figure 8: The low-temperature district heating network with black solid dots denoting load nodes

Table 1: DH network dimensions

\begin{tabular}{llll}
\hline Pipe type & Inner diameter $[\mathrm{mm}]$ & Roughness $[\mathrm{mm}]$ & Length $[\mathrm{m}]$ \\
\hline Alx $32 / 32$ & 26 & 0.02 & 260 \\
Alx $26 / 26$ & 20 & 0.02 & 110 \\
Alx 20/20 & 15 & 0.02 & 100 \\
Alx 16/16 & 11.6 & 0.02 & 75 \\
Alx 14/14 & 10 & 0.02 & 420 \\
\hline
\end{tabular}

The LVN shares the same topology as the DHN in Figure 8 and a single-line diagram is shown in Figure 10. The district is connected to the external grid via a $10 / 0.4 \mathrm{kV}$ transformer. Optimal design of the network was not considered. Cables were selected from commercially available products and the dimensions are summarized in Table 2.

The low-energy building SH demand profile was simulated using IDA ICE [30]. The $\mathrm{SH}$ load is treated here as a fixed base load in DHN. The DHW heating demand was obtained from the EHB model and controller described in section 2.4. The water draw profile was created using Danish Standard [29], which features a large amount of water drawn for showers in the morning and evening. The electricity load was created using a typical Danish residential load profile [31], which gives the base electricity load excluding electric heating. The load diversity was emulated by scaling and shifting the water draw, 


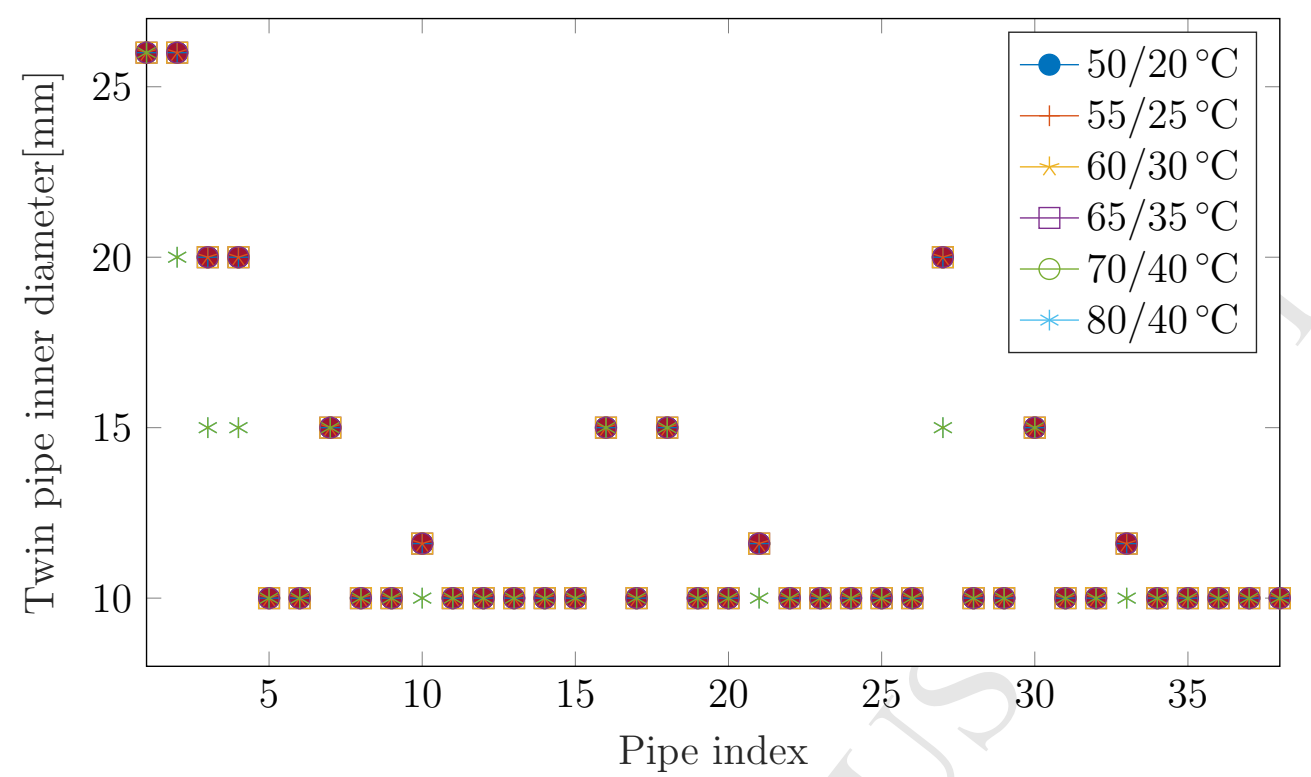

Figure 9: Pipe selection results

Table 2: LVN cable dimension

\begin{tabular}{lllll}
\hline Cable type & Current Value $[\mathrm{A}]$ & $\mathrm{R}[\mathrm{ohm} / \mathrm{km}]$ & $\mathrm{X}[\mathrm{ohm} / \mathrm{km}]$ & Length $[\mathrm{m}]$ \\
\hline 4x150 AL-M PVIKS & 275 & 0.206 & 0.073 & 200 \\
4x95 AL-M PVIKS & 215 & 0.320 & 0.075 & 60 \\
4x16 AL PVIK & 81 & 1.91 & 0.085 & 135 \\
2x6 CU PVIK & 68 & 3.08 & 0.092 & 570 \\
\hline
\end{tabular}

SH demand, and electricity load profiles in accordance with normal distribution $\mathcal{N}\left(\mu, \sigma^{2}\right)$ and uniform distribution $\mathcal{U}\left(\Delta t_{\min }, \Delta t_{\max }\right)$. Heating loads were then all scaled to correspond to BR15 22. It was not necessary to diversify EHB tank size, since commercial products have only a limited number of sizes. We therefore assumed a storage tank of 92 litres for all households. Details found be found in Table 3.

\subsection{Fuel-shift controller design}

The term FS can be explained as replacing one energy source with another. Using the Energy Hub modelling technique proposed by Geidl and Andersson [32], FS can be formulated as Equation 17 and is illustrated in Figure 11. It can be interpreted as an optimized dispatch of $\mathbf{P}_{\text {in }}$ given the load and a predefined cost function.

$$
\mathbf{P}_{\text {out }}=\mathbf{C P}_{\text {in }}
$$

Before designing the controller, practical concerns need to be addressed. EHBs are controlled to shift from one energy source to another, but electric power set points cannot be shared equally between households due to the fixed electric power rating (either $3 \mathrm{~kW}$ or 


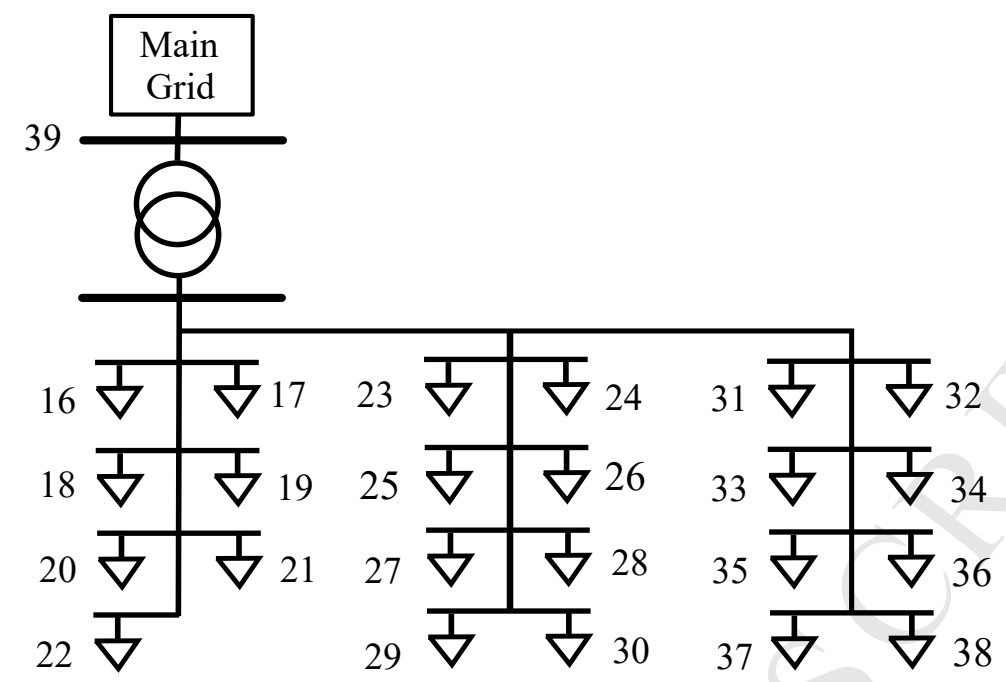

Figure 10: Low-voltage network

Table 3: Assumed stochastic parameters for load diversity

\begin{tabular}{llll}
\hline Variable & Meaning & Distribution & Parameter \\
\hline$P_{\text {daily }}$ & base electricity load peak & Normal & $\mu=7 \mathrm{~kW}, \sigma=0.7 \mathrm{~kW}$ \\
$\Delta t_{\text {el,daily }}$ & time shift of electricity load & Uniform & $\Delta t_{\mathrm{el}, \min }=-1 \mathrm{~h}, \Delta t_{\mathrm{el}, \max }=2 \mathrm{~h}$ \\
$\Phi_{\mathrm{SH}, \text { daily }}$ & SH load peak & Normal & $\mu=1.8 \mathrm{~kW}, \sigma=0.2 \mathrm{~kW}$ \\
$\Delta t_{\mathrm{SH}, \text { daily }}$ & time shift of SH load & Normal & $\mu=0 \mathrm{~h}, \sigma=2 \mathrm{~h}$ \\
$\dot{m}_{\text {tap,daily }}$ & peak tap water draw & Normal & $\mu=10 \mathrm{l} / \mathrm{min}, \sigma=0.2 \mathrm{l} / \mathrm{min}$ \\
$\Delta t_{\text {tap,daily }}$ & time shift of water draw & Normal & $\mu=0 \mathrm{~h}, \sigma=3 \mathrm{~h}$ \\
\hline
\end{tabular}

zero). This means that some EHBs would be supplied by electricity while others would not. Then there is the issue of fairness when coordinating which EHBs should switch from DH to electricity. This is a problem when the price of electricity is much higher than $\mathrm{DH}$, as in Denmark. Moreover, direct control is intrusive. To solve these problems, it was assumed that an entity such as a District Heating Operator (DHO) or Aggregator manages the EHBs. The DHO/Agg would provide heat comfort as a service to consumers, while providing FS to the DHN. This allows the maximum controllability. Any increased electricity cost would be covered by the DHO/Agg.

The FS service would be characterized by the calculation of a power quota based on the heat load desired.

$$
\Phi_{\text {quo }}=\max \left\{\Phi_{\text {des }}-\Phi_{\mathrm{SH}}^{\mathrm{est}}-\Phi_{\mathrm{loss}}^{\mathrm{est}}, 0\right\}
$$

where $\Phi_{\text {des }}$ is the heat load desired in the DHN, $\Phi_{\mathrm{SH}}^{\mathrm{est}}$ and $\Phi_{\text {loss }}^{\text {est }}$ are respectively the estimated SH load and heat losses in the DHN. The quota $\Phi_{\text {quo }}$ for DH load for DHW is then broadcast to the EHBs.

The interactions between the DHO/Agg and the EHBs are illustrated in Figure 12, First, the quota calculated using Equation 18 is broadcast to EHBs. The responsive ones will acknowledge the message; otherwise communication is assumed to have been lost. The 


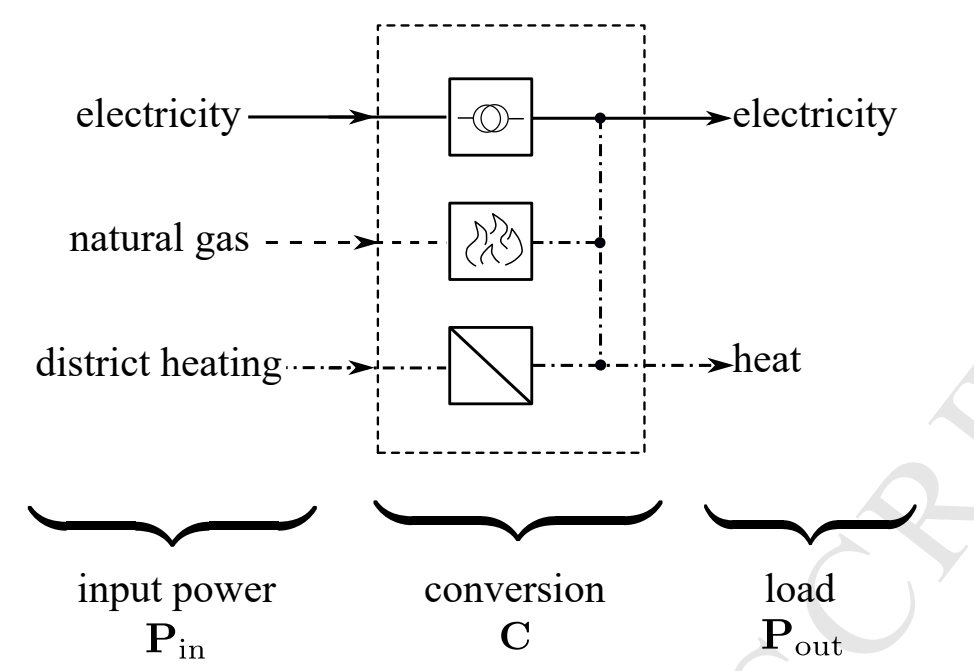

Figure 11: FS explained using Energy Hub modelling technique

EHBs then coordinate among themselves according to their priority. This is determined according to the distance of the load nodes from the heat entry point (node 39 in Figure 8). Those further away will be given lower priority, since long distance heat delivery means more losses and longer delivery time. When the EHBs reach a consensus, a final aggregate DH power for DHW will be reported back to DHO/Agg. In this way, occupancy will not be revealed and privacy will not be compromised.

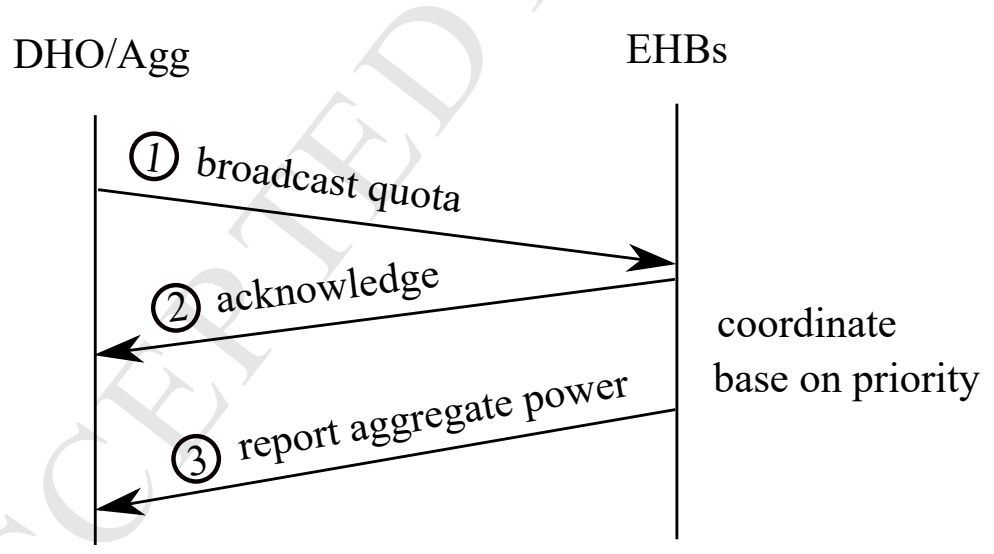

Figure 12: Interaction of DHO/Agg and EHBs in one cycle

\section{Case studies}

The objectives of the analyses here were twofold. Firstly, we wanted to quantify the impacts of supply temperature level on the operation of LTDH networks and the LVN with a detailed EHB model and controller. Secondly, we wanted to evaluate the design FS service using EHBs as flexible resources. 


\subsection{Case 1 - the base case}

In the base case, EHBs are used only as a heat-boosting solution. Annual simulation results for the whole district are summarized in Table 4. We chose a 5-minute time step, since most water draws are less than 5 minutes and this is enough time for water to flow from the entry point to the furthest node. EL and DH in Table 4 refer to using electricity and district heating as the energy source, while DHW, SH, pumps and losses refer to the reason for the energy usage. DH total refers to the total energy used in the DH network, including heat load, network losses, and pump electricity consumption.

Table 4: Energy usage - the base case

\begin{tabular}{l|lllll}
\hline & \multicolumn{5}{|c}{ Supply temperature level $T_{\mathrm{s}}$} \\
\cline { 2 - 6 } Energy [MWh] & $50{ }^{\circ} \mathrm{C}$ & $55^{\circ} \mathrm{C}$ & $60{ }^{\circ} \mathrm{C}$ & $65^{\circ} \mathrm{C}$ & $70{ }^{\circ} \mathrm{C}$ \\
\hline EL DHW & 32.87 & 21.01 & 1.76 & 0.00 & 0.00 \\
DH DHW & 20.74 & 32.38 & 51.36 & 52.93 & 52.79 \\
DH SH & 65.00 & 65.00 & 65.00 & 65.00 & 65.00 \\
DH losses & 23.56 & 26.51 & 29.89 & 33.00 & 36.42 \\
DH pumps & 0.44 & 0.73 & 0.88 & 0.92 & 0.96 \\
DH total & 109.73 & 124.61 & 147.13 & 151.85 & 155.18 \\
\hline
\end{tabular}

Table 4 shows that when $T_{\mathrm{s}}$ is reduced from $70^{\circ} \mathrm{C}$ to $50{ }^{\circ} \mathrm{C}$, losses are reduced by $35 \%$ from 36.42MWh down to 23.56MWh, which approximates to the annual energy consumption of three houses. Moreover, DH is used less for DHW while electricity usage increases due to boosting needs. No control is deployed for SH and the total consumed energy stays the same for all supply temperature levels. The energy balance chart shown in Figure 13 illustrates how the energy in $\mathrm{DH}$ is distributed.

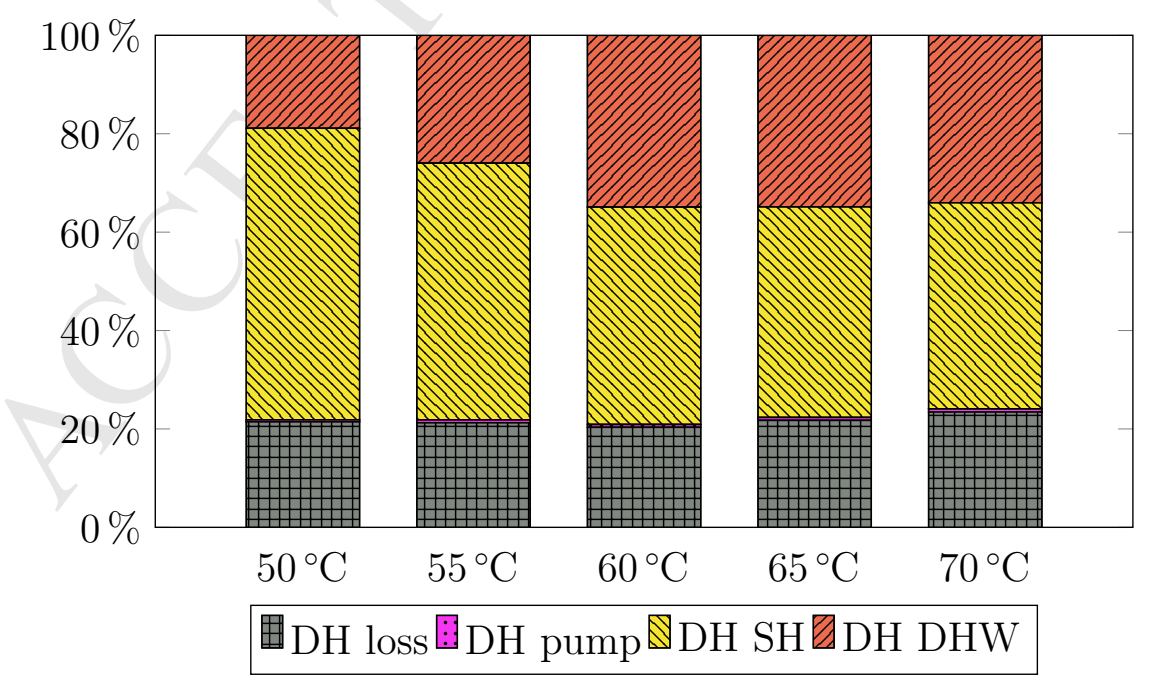

Figure 13: DH energy balance chart - the base case 
Interestingly, Figure 13 shows that losses comprise roughly $21 \sim 24 \%$ of total DH energy when $T_{\mathrm{s}}$ is reduced from $70^{\circ} \mathrm{C}$ to $50^{\circ} \mathrm{C}$, even though losses are substantially reduced in absolute terms. This can be explained by Figure 14, which shows that DH utilized for DHW is reduced by as much as $61 \%$ at the lower supply temperature. With a fixed DHN dimension, when less heat is consumed, there is less pipe flow and higher losses occur. This means that, in percentage terms, the loss reduction benefit is not significant when operating at a lower temperature.

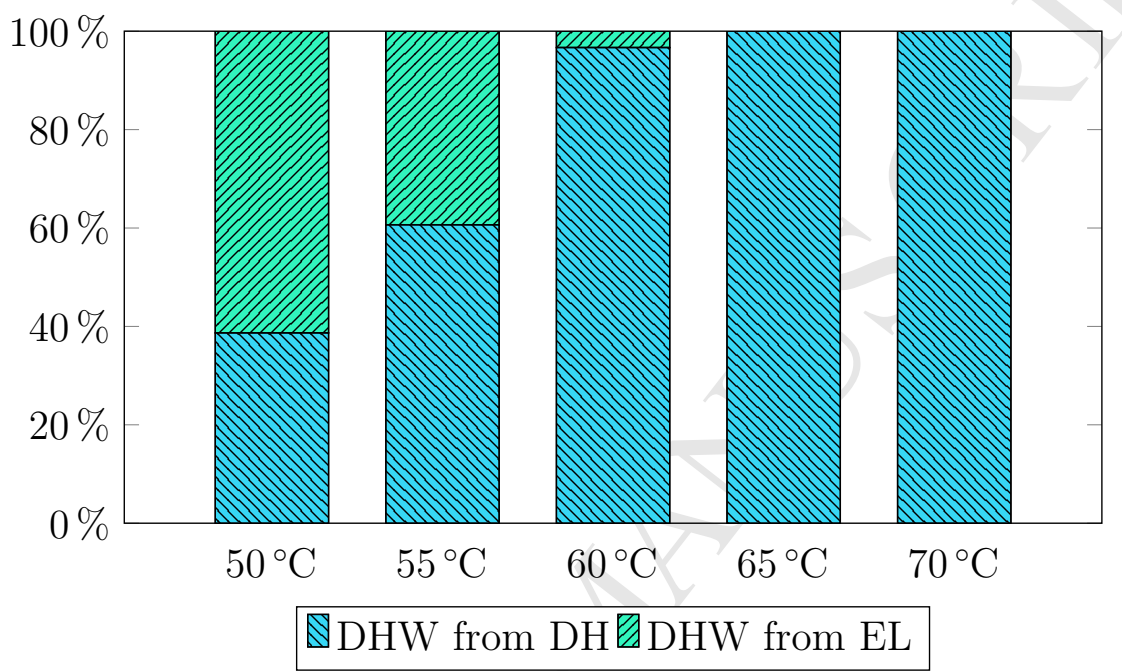

Figure 14: DHW energy source - the base case

Figure 15 shows the load duration curves for selected temperature levels $\left(T_{\mathrm{s}}\right.$ at $50{ }^{\circ} \mathrm{C}$, $60^{\circ} \mathrm{C}$ and $70^{\circ} \mathrm{C}$ ). If we assume that base heat production can cover the heat load for $80 \%$ of the year and the rest will be supplemented by a peak boiler that runs on fossil fuels, the base heat production and fuel usage can be derived from Figure 15.

The LVN power flow analysis result is summarized in Table 5. The increased LVN losses $\Delta E_{\text {loss }}$ and peak power $\Delta P_{\text {peak }}$ were calculated by deducting the base electricity load described in section 2.5. With $\Delta E_{\text {loss }}$ and $\Delta P_{\text {peak }}$, the impact of EHBs can be evaluated. In particular, a substantial increase in peak power $\Delta P_{\text {peak }}$ would require a larger fuse and transformer at the entry of this district. That would be an additional cost that would need to be considered at the planning stage. Table 5 shows that losses due to increased electricity usage could increase by as much as $9 \%$, whereas peak power only increased by about $2 \%$, which means that an upgrade of transformer or fuse is not necessary. The reason for the modest increase in peak power is the difference between electricity and heat load pattern. While standard demand profiles were used in the study, it could be updated with a more detailed consumption pattern analysis obtained from real measurements using a data-driven approach.

Further interpretation of Table 4 and Figure 13 can give interesting results. For instance, while loss reduction and more efficient heat recovery are obvious benefits for the DHN, an increased energy bill is expected as $T_{\mathrm{s}}$ is decreased. Consequently, a trade-off needs to be 


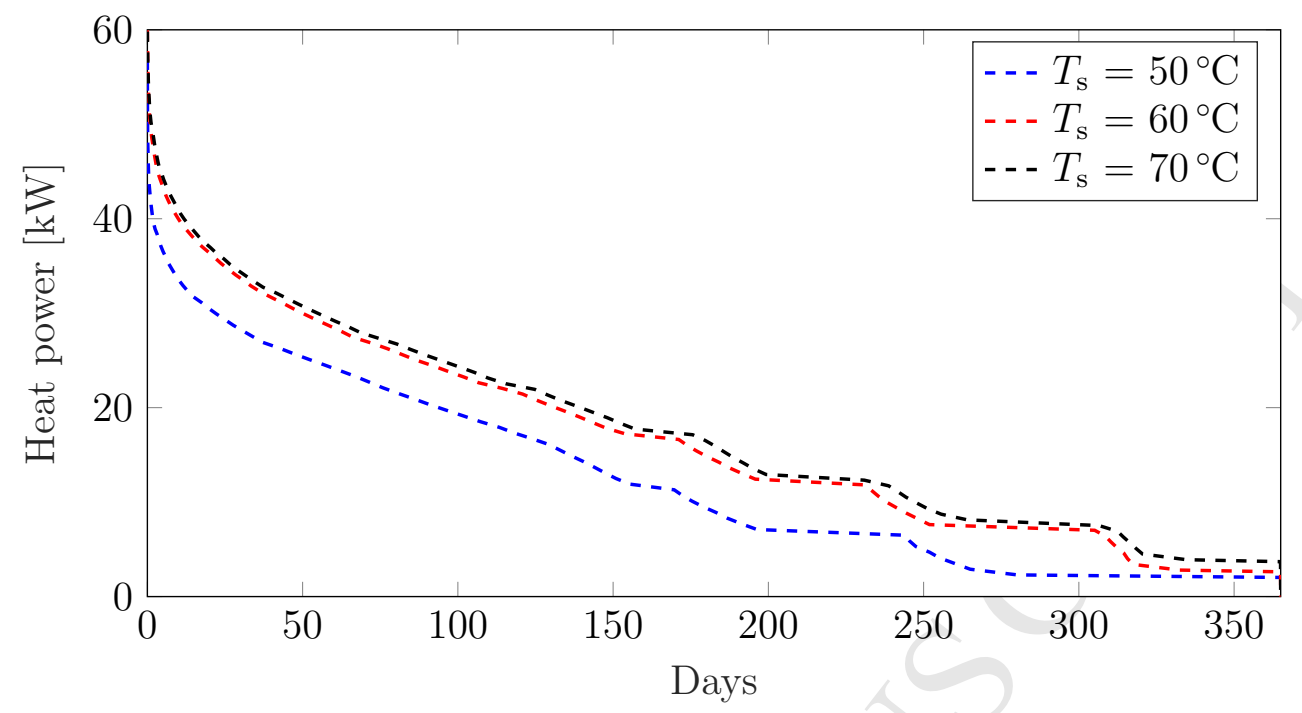

Figure 15: Load duration curves for total DH load at selected $T_{\mathrm{s}}$ levels

Table 5: Impacts of EHBs on the LVN - the base case

\begin{tabular}{l|lllll}
\hline & \multicolumn{5}{|c}{ Supply temperature level $T_{\mathrm{s}}$} \\
\cline { 2 - 6 } & $50^{\circ} \mathrm{C}$ & $55^{\circ} \mathrm{C}$ & $60{ }^{\circ} \mathrm{C}$ & $65^{\circ} \mathrm{C}$ & $70{ }^{\circ} \mathrm{C}$ \\
\hline EL DHW $[\mathrm{MWh}]$ & 32.87 & 21.01 & 1.76 & 0.00 & 0.00 \\
LVN $\Delta E_{\text {loss }}[\mathrm{MWh}]$ & 4.80 & 3.05 & 0.24 & 0.00 & 0.00 \\
LVN $\Delta E_{\text {loss }}[\%]$ & 9.14 & 5.81 & 0.46 & 0.00 & 0.00 \\
$\Delta P_{\text {peak }}[\mathrm{kVA}]$ & 2.50 & 3.60 & 0.00 & 0.00 & 0.00 \\
$\Delta P_{\text {peak }}[\%]$ & 1.52 & 2.19 & 0.00 & 0.00 & 0.00 \\
\hline
\end{tabular}

found in terms of $T_{\mathrm{s}}$. To do so, the numerical relationships between each energy usage and $T_{\mathrm{s}}$ need to be found. Interpolation was used in this research to derive the relationships. Since Table 4 shows no difference between $65^{\circ} \mathrm{C}$ and $70^{\circ} \mathrm{C}$ other than $\mathrm{DH}$ losses, to obtain a good fit, interpolation was only done for temperature levels from $50{ }^{\circ} \mathrm{C}$ to $65^{\circ} \mathrm{C}$. The results are summarized in Table 6 , where parameters in linear and quadratic interpolation refer to $E=a T_{\mathrm{s}}+b$ and $E=a T_{\mathrm{s}}^{2}+b T_{\mathrm{s}}+c$ respectively. Subject to the fit level in terms of root-mean-square error (RMSE), Equation 19 can be obtained.

Table 6: Numerical relationships between energy usage and $T_{\mathrm{s}}$

\begin{tabular}{c|ccc|cccc}
\hline & \multicolumn{3}{|c|}{ Linear interpolation } & \multicolumn{4}{c}{ Quadratic interpolation } \\
\cline { 2 - 8 } & $\mathrm{a}$ & $\mathrm{b}$ & RMSE & $\mathrm{a}$ & $\mathrm{b}$ & $\mathrm{c}$ & RMSE \\
\hline EL DHW [MWh] & -2.36 & 149.45 & 7.51 & 0.10 & -13.97 & 480.22 & 5.56 \\
DH losses [MWh] & 0.63 & -8.22 & 0.18 & 0.00 & 0.45 & -2.98 & 0.16 \\
DH total [MWh] & 2.98 & -37.88 & 7.63 & -0.10 & 14.66 & -370.62 & 5.69 \\
\hline
\end{tabular}




$$
\begin{aligned}
E_{\mathrm{el}}\left(T_{\mathrm{s}}\right) & =0.1 T_{\mathrm{s}}^{2}-13.97 T_{\mathrm{s}}+480.22 \\
E_{\mathrm{loss}}\left(T_{\mathrm{s}}\right) & =0.63 T_{\mathrm{s}}-8.22 \\
E_{\mathrm{dh}}\left(T_{\mathrm{s}}\right) & =-0.1 T_{\mathrm{s}}^{2}+14.66 T_{\mathrm{s}}-370.62
\end{aligned}
$$

\subsection{Case 2 - fuel shift}

To further improve the benefits of EHBs and exemplify their active roles in a SES, the FS service was first and foremost designed to assist DHN operation. The impacts of FS can then be evaluated by interpreting the results of the annual analysis.

The annual analysis was performed assuming perfect forecasts of SH load and heat loss, and perfect communication and coordination. Impacts on DHN for the case $\Phi_{\text {des }}=20 \mathrm{~kW}$ are summarized in Table 7, Figure 16 and Figure 17, while the impacts on LVN are summarized in Table 8 and Table 9. Compared to Table 4, Figure 13 and Figure 14, electricity usage is higher while DH energy consumption is lower. Heat loss is slightly higher due to reduced heat load. Moreover, Table 8 implies that EHBs' increased electricity consumption would not need an upgrade in LVN.

Table 7: Energy usage and when $\Phi_{\text {des }}=20 \mathrm{~kW}$

\begin{tabular}{l|lllll}
\hline & \multicolumn{5}{|c}{ Supply temperature level $T_{\mathrm{s}}$} \\
\cline { 2 - 6 } Energy [MWh] & $50^{\circ} \mathrm{C}$ & $55^{\circ} \mathrm{C}$ & $60^{\circ} \mathrm{C}$ & $65^{\circ} \mathrm{C}$ & $70{ }^{\circ} \mathrm{C}$ \\
\hline EL DHW & 38.68 & 30.51 & 17.91 & 16.75 & 16.67 \\
DH DHW & 14.91 & 22.85 & 35.16 & 36.13 & 36.07 \\
DH SH & 65.00 & 65.00 & 65.00 & 65.00 & 65.00 \\
DH losses & 23.89 & 26.90 & 30.41 & 33.71 & 37.25 \\
DH pumps & 0.13 & 0.14 & 0.16 & 0.17 & 0.18 \\
DH total & 103.93 & 114.89 & 130.73 & 135.00 & 138.50 \\
\hline
\end{tabular}

New load duration curves were obtained and are summarized in Figure 18, which shows a clear reduction of in peak-load hours. Figure 19 shows values for the reduced base heat power production and peak boiler usage compared with the case without FS. The results show that, with the FS service, base heat power production for the DHN can be reduced by as much as $15 \%$, and for peak boiler usage by as much as $48 \%$.

Reduced peak heat power means that existing network could connect more buildings without an upgrade (such as pipes with wider inner diameters). It also implies that a smaller size of CHP plant could be possible. Moreover, peak boiler usage reduction could contribute to a $100 \%$ renewable-based electricity and heating sector by 2035 .

The results presented in these two case studies can be used as input for future economic analysis. For example, the reduced base heat power production, losses and peak boiler usage all contribute to reduction of investment and operation cost, while increased electricity consumption represents increased operation cost. Combining with the relationships obtained in Equation 19, an optimal supply temperature that minimizes life cycle cost could be obtained. In-depth economic evaluation lies outside of the scope of this paper. 


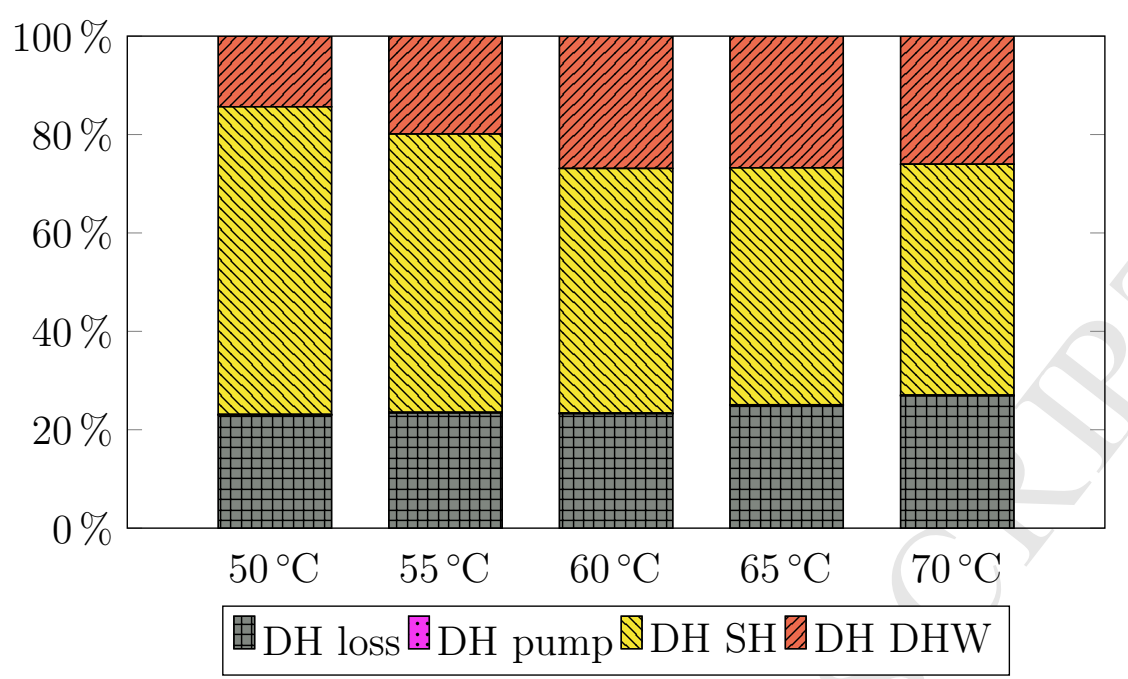

Figure 16: Energy balance chart with FS and $\Phi_{\text {des }}=20 \mathrm{~kW}$

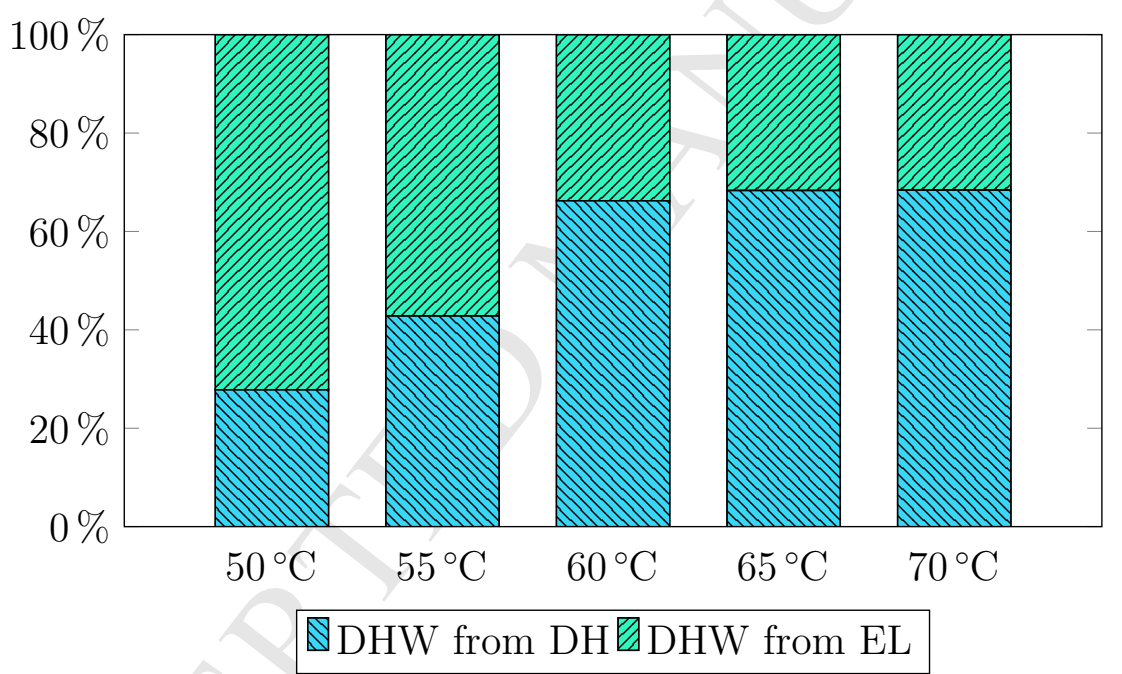

Figure 17: DHW energy source with FS and $\Phi_{\text {des }}=20 \mathrm{~kW}$

In summary, this case study demonstrates that intelligent residential substations with EHBs could contribute to synergy between electricity and heat sectors.

\section{Conclusions and future work}

Cross-sector flexible resource use of EHBs in low-energy districts was investigated based on combined heat and power analysis. A hypothetical district with 23 terraced single-family houses supplied by both an LTDH network and an LVN was analysed and two case studies were performed. The first case focused on the impact of LTDH supply temperature levels. Comparisons were made for annual heat and power flow analysis results at five different supply temperature levels. Results show that DHN heat losses can be reduced by $35 \%$ when 
Table 8: Impacts of EHBs on the LVN with FS, $\Phi_{\text {des }}=20 \mathrm{~kW}$

\begin{tabular}{l|lllll}
\hline & \multicolumn{5}{|c}{ Supply temperature level $T_{\mathrm{s}}$} \\
\cline { 2 - 6 } & $50^{\circ} \mathrm{C}$ & $55^{\circ} \mathrm{C}$ & $60^{\circ} \mathrm{C}$ & $65^{\circ} \mathrm{C}$ & $70^{\circ} \mathrm{C}$ \\
\hline EL DHW $[\mathrm{MWh}]$ & 38.68 & 30.51 & 17.91 & 16.75 & 16.67 \\
$\mathrm{LVN} \Delta E_{\text {loss }}[\mathrm{MWh}]$ & 5.81 & 4.69 & 3.01 & 2.87 & 2.85 \\
$\mathrm{LVN} \Delta E_{\text {loss }}[\%]$ & 11.07 & 8.94 & 5.74 & 5.46 & 5.44 \\
$\Delta P_{\text {peak }}[\mathrm{kVA}]$ & 7.10 & 4.90 & 5.60 & 5.60 & 5.60 \\
$\Delta P_{\text {peak }}[\%]$ & 4.32 & 2.98 & 3.41 & 3.41 & 3.41 \\
\hline
\end{tabular}

Table 9: Impacts of EHBs on the LVN - comparing the base case with FS, $\Phi_{\text {des }}=20 \mathrm{~kW}$

\begin{tabular}{l|lllll}
\hline & \multicolumn{5}{|c}{ Supply temperature level $T_{\mathrm{s}}$} \\
\cline { 2 - 6 } & $50^{\circ} \mathrm{C}$ & $55^{\circ} \mathrm{C}$ & $60{ }^{\circ} \mathrm{C}$ & $65^{\circ} \mathrm{C}$ & $70{ }^{\circ} \mathrm{C}$ \\
\hline$\Delta P_{\text {peak }}[\%]$ & 1.52 & 2.19 & 0.00 & 0.00 & 0.00 \\
$\Delta P_{\text {peak }}[\%]$ & 4.32 & 2.98 & 3.41 & 3.41 & 3.41 \\
\hline
\end{tabular}

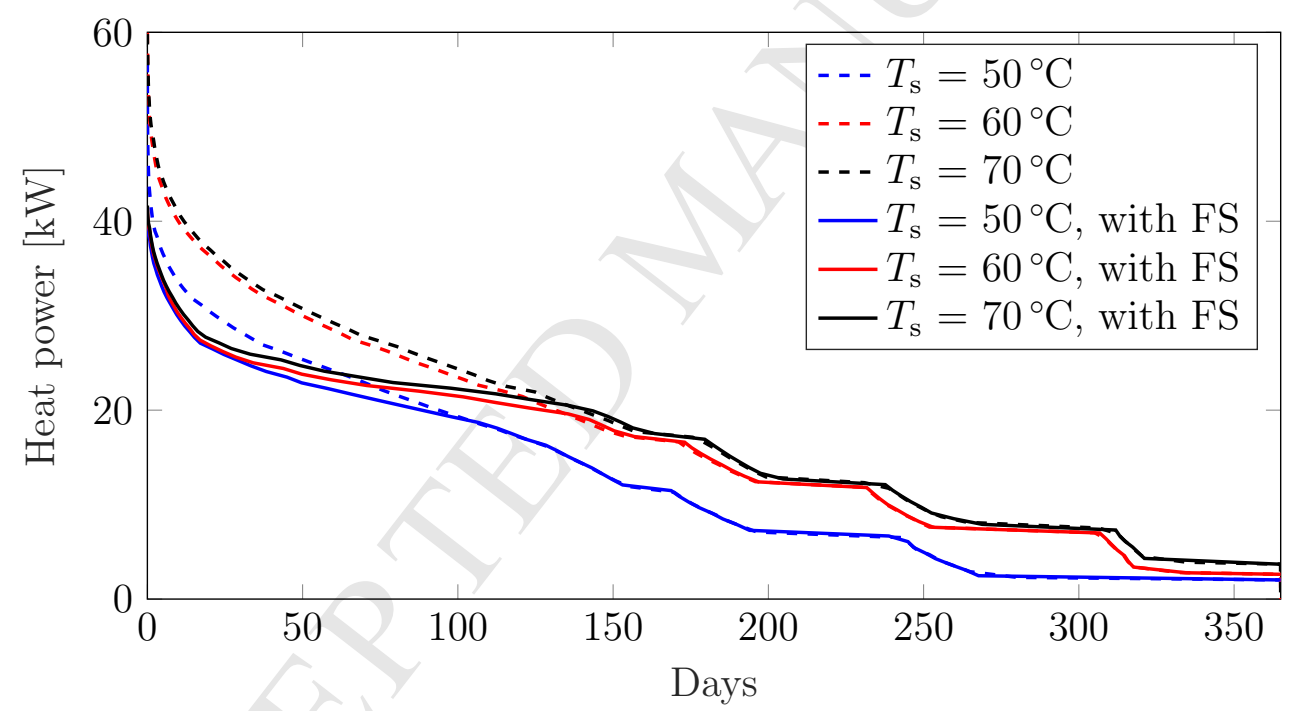

Figure 18: Impact of fuel shift on load duration curves with $\Phi_{\text {des }}=20 \mathrm{~kW}$. Dashed lines are load duration curves without FS, solid lines are those with FS

the supply temperature is reduced from $70^{\circ} \mathrm{C}$ to $50^{\circ} \mathrm{C}$, but the LVN peak power will have to be increased by up to $2 \%$ using heat boosting. The second case provides the design of an FS service for the DHN. Analysis was carried out at the same five supply temperature levels. Results show that LVN peak power is increased by up to $4.3 \%$, while basic power production for DHN can be reduced by as much as $15 \%$ and peak boiler usage by as much as $48 \%$. The reduced heat demand can be taken into account in future network planning. This could make it possible to further reduce network dimensions and losses. The results obtained can also be used as input for economic evaluation. Therefore this study makes an important contribution to the research on $4 \mathrm{GDH}$ by demonstrating the usefulnesses of lower 


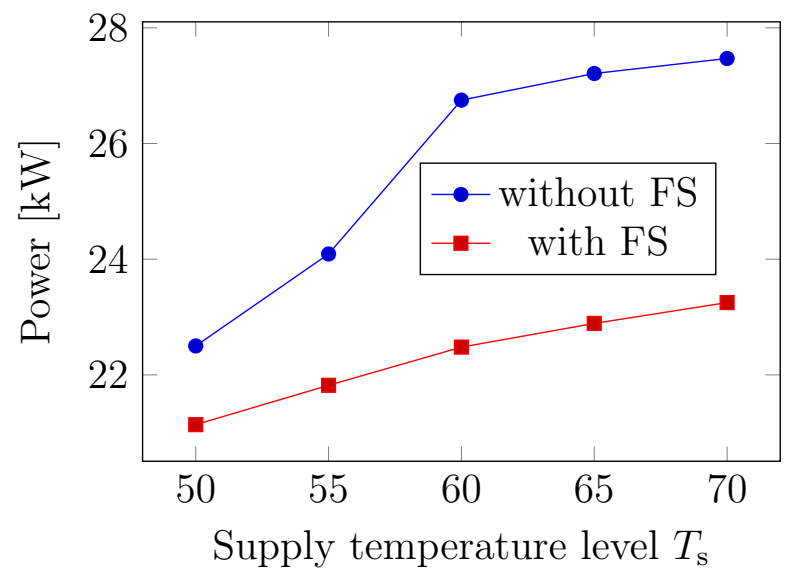

(a) $\mathrm{DH}$ base power production

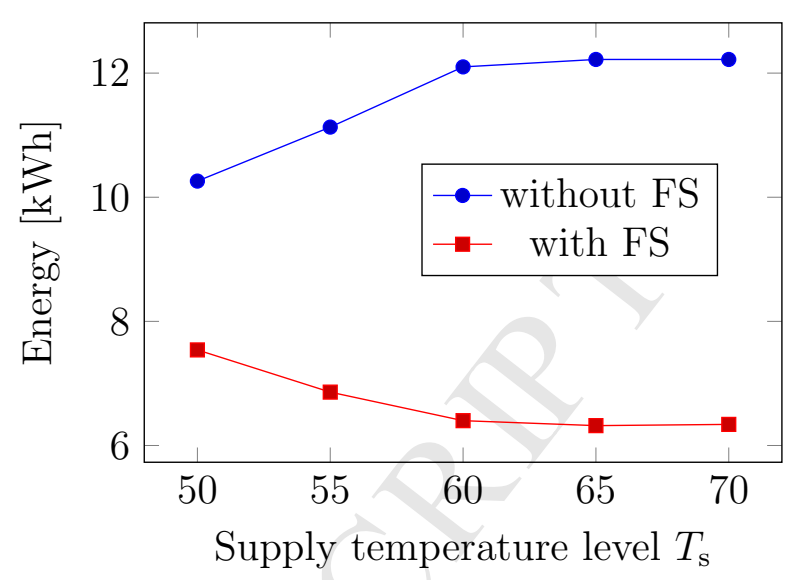

(b) Peak boiler usage

Figure 19: Impact of fuel shift on base production capacity and fuel usage for peak boiler. Results without FS (in blue) and with FS, $\Phi_{\text {des }}=20 \mathrm{~kW}$ (in red)

supply temperature and intelligent residential substations.

Several aspects of this work could be improved and extended. Steady-state analysis of a DHN does not give a perfect representation of the real DH system. Dynamics, such as heat transfer delays, could be added in the future to enable simulation of the dynamic operation of a DHN and exploit its storage capacity to absorb excess wind power. Moreover, heat pump boosters might be more cost-efficient in multi-family buildings due to their lower operation cost. A better mix of technologies could be achieved. Lastly, the fuel shift service described here is an LVN passive response to the needs of the DHN. In an integrated energy system, network operation challenges for both electricity and district heating networks need to be addressed. The difference is that there are power-to-heat devices available in residential substations, but no heat-to-power conversion devices on the end-user side. This means there is no single solution that can address both challenges.

As a part of the Danish Energy Technology Development and Demonstration Programme, the concepts and solutions developed in this paper will be demonstrated in the Nordhavn area in Copenhagen, Denmark with some modifications. 24 houses have volunteered to participate and all have been equipped with the DH substations mentioned in this paper. Laboratory tests have shown EHBs are capable of switching between FS and non-FS modes. A large-scale experiment is expected to be rolled out. 23 houses will be aggregated to provide the FS service and one house will be left out for comparison.

\section{Acknowledgement}

This research was part of a project which is funded by the Danish EUDP (Energy Technology Development and Demonstration Programme). Project title: EnergyLab Nordhavn

- Smart components in integrated energy systems, project number: 64015-0055. 


\section{References}

[1] The Danish Government, The Danish Climate Policy Plan Towards a low carbon society (2013).

[2] The Danish Transport and Construction Agency, Danish Building Regulations 2015 (BR15), Copenhagen.

[3] H. Lund, P. A. Østergaard, D. Connolly, B. V. Mathiesen, Smart energy and smart energy systems, Energy 137 (2017) 556-565.

[4] H. Lund, S. Werner, R. Wiltshire, S. Svendsen, J. E. Thorsen, F. Hvelplund, B. V. Mathiesen, 4th Generation District Heating (4GDH): Integrating smart thermal grids into future sustainable energy systems, Energy 68 (2014) 1-11.

[5] H. Lund, Renewable energy systems: a smart energy systems approach to the choice and modeling of 100\% renewable solutions, Academic Press, 2014.

[6] Nord Pool Spot, Elspot prices. URL http: //www . nordpoolspot . com/

[7] F. Hvelplund, P. A. Østergaard, N. I. Meyer, Incentives and barriers for wind power expansion and system integration in Denmark, Energy Policy 107 (2017) 573-584.

[8] B. Bach, J. Werling, T. Ommen, M. Münster, J. M. Morales, B. Elmegaard, Integration of large-scale heat pumps in the district heating systems of Greater Copenhagen, Energy 107 (2016) 321-334.

[9] P. Mancarella, MES (multi-energy systems): An overview of concepts and evaluation models, Energy 65 (2014) 1-17.

[10] Z. Li, W. Wu, M. Shahidehpour, J. Wang, B. Zhang, Combined heat and power dispatch considering pipeline energy storage of district heating network, IEEE Transactions on Sustainable Energy 7 (1) (2016) 12-22.

[11] H. Cai, S. You, H. W. Bindner, S. Klyapovskiy, Load Situation Awareness Design for Integration in Multi-Energy System, in: Energy Internet (ICEI), IEEE International Conference on, IEEE, 2017, pp. $42-47$.

[12] H. Cai, S. You, H. W. Bindner, S. Klyapovskiy, X. Yang, R. Li, Optimal scheduling for electric heat booster under day-ahead electricity and heat pricing, in: 52nd International Universities Power Engineering Conference (UPEC), 2017, pp. 1-4.

[13] D. S. Østergaard, S. Svendsen, Theoretical overview of heating power and necessary heating supply temperatures in typical Danish single-family houses from the 1900s, Energy and Buildings 126 (2016) $375-383$.

[14] X. Yang, H. Li, S. Svendsen, Alternative solutions for inhibiting Legionella in domestic hot water systems based on low-temperature district heating, Building Services Engineering Research and Technology 37 (4) (2016) 468-478.

[15] E. Zvingilaite, T. S. Ommen, B. Elmegaard, M. L. Franck, Low temperature district heating consumer unit with micro heat pump for domestic hot water preparation, in: 13th International Symposium on District Heating and Cooling, 2012, pp. 136-143.

[16] B.-S. Park, M. Imran, I.-Y. Hoon, M. Usman, Thermo-economic optimization of secondary distribution network of low temperature district heating network under local conditions of South Korea, Applied Thermal Engineering 126 (2017) 117-133.

[17] T. Ommen, J. E. Thorsen, W. B. Markussen, B. Elmegaard, Performance of ultra low temperature district heating systems with utility plant and booster heat pumps, Energy 137 (2017) 544-555.

[18] B. Elmegaard, T. S. Ommen, M. Markussen, J. Iversen, Integration of space heating and hot water supply in low temperature district heating, Energy and Buildings 124 (2016) 255-264.

[19] P. A. Østergaard, A. N. Andersen, Booster heat pumps and central heat pumps in district heating, Applied Energy 184 (2016) 1374-1388.

[20] X. Yang, H. Li, S. Svendsen, Energy, economy and exergy evaluations of the solutions for supplying domestic hot water from low-temperature district heating in Denmark, Energy Conversion and Management 122 (2016) 142-152.

[21] H. Gadd, S. Werner, Heat load patterns in district heating substations, Applied energy 108 (2013) $176-183$. 
[22] K. Ahmed, P. Pylsy, J. Kurnitski, Hourly consumption profiles of domestic hot water for different occupant groups in dwellings, Solar Energy 137 (2016) 516-530.

[23] E. Guelpa, G. Barbero, A. Sciacovelli, V. Verda, Peak-shaving in district heating systems through optimal management of the thermal request of buildings, Energy 137 (2017) 706-714.

[24] C. Johansson, F. Wernstedt, P. Davidsson, Deployment of agent based load control in district heating systems, in: First International Workshop on Agent Technologies for Energy Systems, Canada, 2010.

[25] X. Liu, J. Wu, N. Jenkins, A. Bagdanavicius, Combined analysis of electricity and heat networks, Applied Energy 162 (2016) 1238-1250.

[26] S. Frederiksen, S. Werner, District heating and cooling, Studentlitteratur, 2013.

[27] H. Li, S. Svendsen, Energy and exergy analysis of low temperature district heating network, Energy 45 (1) (2012) 237-246.

[28] DVGW W 551:2004-04, Deutscher Verein des Gas- und Wasserfaches eV (German Technical and Scientific Association for Gas and Water), Code of Practice, Drinking water heating and drinking water piping systems.

[29] DS 439:2009, Danish Standards, Code of Practice for Water Supply Installations.

[30] H. Pieper, T. Ommen, W. B. Markussen, B. Elmegaard, Optimal usage of low temperature heat sources to supply district heating by heat pumps, in: 30th International Conference on Efficiency, Cost, Optimization, Simulation and Environmental Impact of Energy Systems, 2017.

[31] Danish Electricity Consumption Panels, Reports, Profiles 2012 (in Danish) URL http://www.elforbrugspanel.dk/Pages/Rapportering.aspx

[32] M. Geidl, G. Andersson, Optimal power flow of multiple energy carriers, IEEE Transactions on Power Systems 22 (1) (2007) 145-155. 


\section{Highlights:}

- Comprehensive model of heat and power network flow for steady-state simulation.

- Analysis of the performance of a low-energy district in 5-minute intervals.

- Detailed electric heat booster model and controller design in a real-world context.

- Design of fuel shift service for the district heating sector to optimize operation.

- Analysis of the advantages of lower supply temperatures and smart components. 